СПИСАНИЕ НА БЪЛГАРСКОТО ГЕОЛОГИЧЕСКО ДРУЖЕСТВО, год. 82, кн. 3, 2021, с. 186-188

REVIEW OF THE BULGARIAN GEOLOGICAL SOCIETY, vol. 82 , part 3, 2021, p. 186-188

\title{
Determination of the content of natural radionuclides in rock materials used in the buildings
}

\section{Определяне сьдьржанието на естествени радионуклиди в скални материали, използвани в строителството}

\section{Ekaterina Serafimova ${ }^{1}$, Vilma Petkova ${ }^{2}$ Екатерина Серафимова ${ }^{1}$ Вилма Петкова ${ }^{2}$}

\footnotetext{
${ }^{1}$ University of Chemical Technology and Metallurgy, 8 K1. Ohridski Blvd., 1756 Sofia; E-mail: ekaterina_sr@uctm.edu

${ }^{2}$ Institute of Mineralogy and Crystallography, Bulgarian Academy of Sciences, Acad. G. Bonchev Str., bldg. 107, 1113 Sofia; E-mail: vilmapetkova@gmail.com
}

\begin{abstract}
The negative impact of natural inorganic building materials on people during their life cycle can be potentially significant, in case of presence of radionuclides, due to the very long period of negative radioactive impact. International experience shows that effective prevention of public health and reduction of exposure involves a wide range of actions, which has been achieved through the development and preparation of a strategy at the national level. The content of natural radionuclides in rock materials for construction purposes, taken from different buildings in Southern Bulgaria, has been determined. The obtained data are in norms under the Bulgarian legislation, but for some samples with values close to the maximum permissible concentrations.
\end{abstract}

Keywords: natural building materials, radionuclides.

\section{Въведение}

Съдържанието на различни елементи в строителните материали и охарактеризирането на техните кристални структури дават първа представа за евентуални рискове за човешкото здраве при тяхното приложение при изграждането на обществени, семейни и индустриални сгради (Council Directive 96/29/EURATOM, 1996). Именно това е причината все повече изследвания да са насочени към охарактеризирането на изходните суровини и композитните продукти и материали, които се прилагат в практиката.

Причините за установеното по-широко разпространение на тези замърсители в строителните материали във вътрешните помещения, е все по-широкото им приложение при производството на стоки, продукти, изделия и други материали за бита, които имат и естествен произход (Mustonen, 1999). Това се отнася както до внедряването на все по-голям брой строителни продукти и съответно разнообразието на изход- ната суровина, така и от все по-разнообразното им практическо приложение при различни условия в използваните помещения. В допълнение, към традиционно широкоизползваните строителни материали, трябва да се прибавят и широката гама от нови композитни смеси с различно предназначение, прилагани както по време на строителството, така и във вътрешността на помещенията.

Съдържанието на радон в атмосферния въздух обикновено е резултат на радиоактивния разпад и равновесие от намиращите се в природните суровини радиоактивен калий, радий и торий (Commission Recommendation, 1990). За разлика от радона, останалите радиоактивни елементи при попадане в човешкото тяло обикновено се натрупват в скелета (костите) или цялото тяло (Council Directive,1988).

На базата на специфичните характеристики на геоложките структури в страната са избрани обектите, от които е извършено пробоотбиране на използвани скални материали за строителни 
цели и са селектирани точните места за извършването на съответните други проучвания и определения. Те принадлежат към две направления - югоизточно и югозападно. В югоизточното направление са включени обекти от селища (градовете Хасково, Кьрджали, Златоград), а в югозападното са от област Благоевград (градовете Благоевград, Мелник и село Елешница). Отбраните проби са селектирани и подложени на двукратно смилане до необходимата едрина. От пробите са взети необходимите количества за провеждане на анализ с определяне на естествени радионуклиди в строителните материали от отделните обекти.

\section{Подготовка на образци за анализ}

Строшаване на мостри от скални и строителни материали, събрани от различни области, след което са наситнени в мелници за сухо смилане до размер на фракция под $3 \mathrm{~mm}$. Преди строшаването им те са подложени на сушене при $105^{\circ} \mathrm{C}$ до достигане на постоянно тегло.

Хомогенизиране, квартоване и смилане на средна част от вече строшените образци в ахатов хаван в количество $\sim 100 \mathrm{~g}$ до размер на фракцията $-0.063 \mathrm{~mm}$. Основното изискване е пробите да бъдат максимална степен на аналитична възпроизводимост. Гаранция за това е образците да се хомогенизират много добре и тази хомогенност да се запази през цялото време на провеждане на изследването. Използван е делител на Джонсън, който хомогенизира и разделя пробата едновременно.

\section{Използвани методи}

Анализът за съдържание на естествени радионуклиди в проби от скални материали, използвани за строителни цели (определяне индекс на специфична активност), е направен чрез гама-спектрометричен анализ (Erdtmann, 1979) по международен стандарт (IEC 61452:1995).

Гама-спектрометричната система се състои от HPGe (свръхчист германий) коаксиален детектор и цифров спектрометър. Детекторьт модел GMX45P4-83-CW-SMN, фабричен № 52-TN 4225A (с HPGe кристал с обем $226 \mathrm{~cm}^{3}$ и $0.9 \mathrm{~mm}$ тънък фиберкарбонов прозорец) е с гарантирани от производителя относителна ефективност $\varepsilon r$ $=45 \%$ и разделителна способност при енергия $1.33 \mathrm{MeV}$ FWHM = $2.1 \mathrm{keV}$.

Системата е калибрирана с еталонен обемен източник с проследимост до международен еталон (свидетелство за калибриране, издадено от Български институт по метрология, ГД „Национален център по метрология”). Еталонният обемен източник е от същата геометрия, в която се провеждат измерванията - съд Маринели с обем $1 \mathrm{~L}$.

Таблица 1. Резултати от гама спектроскопия на скални материали, използвани в строителството

\begin{tabular}{|c|c|c|c|c|c|}
\hline № & Обект & Материал & ${ }^{40} \mathrm{~K}(\mathrm{~Bq} / \mathrm{kg})$ & ${ }^{226} \mathrm{Ra}(\mathrm{Bq} / \mathrm{kg})$ & ${ }^{232} \mathrm{Th}(\mathrm{Bq} / \mathrm{kg})$ \\
\hline 1. & Кьрджали - ПГЧЕ „Христо Ботев“ & гранит & $1186 \pm 31$ & $90.7 \pm 2.5$ & $22.3 \pm 0.7$ \\
\hline 2. & Златоград - хотел & $\begin{array}{l}\text { деформиран } \\
\text { гранитоид }\end{array}$ & $1259 \pm 33$ & $94.0 \pm 2.3$ & $27.8 \pm 0.9$ \\
\hline 3. & Златоград - болница & $\begin{array}{l}\text { подова настилка } \\
\text { от левкократен } \\
\text { метагранит }\end{array}$ & $1212 \pm 32$ & $58 \pm 8$ & $49,0 \pm 2,1$ \\
\hline 4. & с. Хасковски минерални бани - хотел & $\begin{array}{l}\text { метагранит - } \\
\text { облицовка стени }\end{array}$ & $1176 \pm 30$ & $77 \pm 6$ & $31,1 \pm 1,2$ \\
\hline 5. & с. Винево - къща & гранитогнайс & $477 \pm 13$ & $39,7 \pm 3,6$ & $71,7 \pm 2,3$ \\
\hline 6. & Благоевград - дом за стари хора & гранит & $795 \pm 22$ & $23,4 \pm 0,6$ & $32.5 \pm 1.0$ \\
\hline 7. & $\begin{array}{l}\text { Благоевград - строителна база } \\
\text { „Бодрост“ }\end{array}$ & гранит светъл & $867 \pm 26$ & $21,0 \pm 0,7$ & $29,5 \pm 1,4$ \\
\hline 8. & $\begin{array}{l}\text { Благоевград - строителна база } \\
\text { „Бодрост“ }\end{array}$ & гранит тъмен & $733 \pm 20$ & $71,7 \pm 1,9$ & $79.2 \pm 2,8$ \\
\hline 9. & Мелник - кметство & $\begin{array}{l}\text { спойка подстилаща от } \\
\text { брекчо-конгломерат }\end{array}$ & $996 \pm 28$ & $51,3 \pm 1,3$ & $69,3 \pm 3,3$ \\
\hline 10. & с. Елешница - ОДЗ „Надежда“ & гранит облицовъчен & $1679 \pm 43$ & $159 \pm 19$ & $80 \pm 3,7$ \\
\hline & с. Елешница - частен дом & гранит & $970 \pm 25$ & $34,4 \pm 1,0$ & $45,1 \pm 2,1$ \\
\hline & с. Елешница - частен дом & $\begin{array}{l}\text { подстилаща основа от } \\
\text { брекчоконгломерат с } \\
\text { късове от пегматити }\end{array}$ & $1069 \pm 29$ & $93 \pm 10$ & $63,6 \pm 1,8$ \\
\hline
\end{tabular}




\section{Резултати и дискусия}

По резултати от измерване се изчислява индекс на специфична активност на строителни материали:

$$
I=\frac{C_{K}}{3000 \mathrm{~Bq} / \mathrm{kg}}+\frac{C_{R a}}{300 \mathrm{~Bq} / \mathrm{kg}}+\frac{C_{T h}}{200 \mathrm{~Bq} / \mathrm{kg}},
$$

където $C_{K}, C_{R a}$ и $C_{T h}$ са съответно измерените специфични активности на ${ }^{40} \mathrm{~K},{ }^{226} \mathrm{Ra}$ и ${ }^{232} \mathrm{Th}$. За оценка на съответствието се прилагат максимално допустимите стойности на индекса на специфична активност на строителни материали, установени с чл. 5 от Naredba №25 (2005) за изискванията за защита на лицата при хронично облъчване в резултат на производство, тьрговия и използване на суровини, продукти и стоки с повишено съдържание на радионуклиди. Всички изследвани проби отговарят на изискванията по тази Наредба (табл. 1).

\section{Изводи}

Резултатите от проведените аналитични изследвания показват, че наличието на радионуклиди в скалните материали, използвани за строителни цели, са под пределно допустимите концентрации, съгласно българското законодателство за максимално допустима стойност на индекса на специфична активност за облицовъчни материали за жилищни и обществени сгради. Това вероятно от една страна се дължи на произхода на скалните материали, а от друга на факта, че обследваните сгради са на повече от 20 години. Въпреки получените резултати, рискът при строителството на нови сгради за използване на скални материали, генериращи радионуклиди, остава. Необходимо е разработване на национална политика за контрол на строителните материали, с цел превенция в областта на общественото здраве и намаляване на риска за населението от експозиция на радионуклиди във вътрешен въздух в помещенията.

Благодарности: Изследването е подкрепена от Оперативна програма „Наука и образование за интелигентен растеж“, съфинансирана от Европейския сьюз чрез Европейските структурни и инвестиционни фондове по грант BG05M2OP001-1.001-0008 на Национален център по мехатроника и чисти технологии.

\section{Литература \\ References}

Council Directive 96/29/EURATOM of 13 May 1996 laying down the basic safety standards of the health of workers and the general public against the danger arising from ionising radiation.

Commission Recommendation of 21 February 1990 on the protection of the public against indoor exposure to radon.

Council Directive of 21 December 1988 on the approximation of laws, regulations and administrative provisions of the Member States related to construction products.

Erdtmann, G., W. Soyka. 1979. The Gamma-Rays of the Radionuclides: Tables for Applied Gamma-Ray Spectrometry, Vol. 7. Weinheim, New York, Verlag Chemie: 236 p.

IEC 61452:1995-09 Nuclear instrumentation - Measurement of Gamma-ray Emission Rates of Radionuclides - Calibration and Use of Germanium Spectrometers. International Electrotechnical Commission, Geneva.

Mustonen, R., M. Pennanen, M. Annanmäki, E. Oksanen. 1999. Enhanced Radioactivity of Building Materials. Final report of the contract No 96-ET-003 for the European Commission. Radiation and Nuclear Safety Authority - STUK, Finland, 96 p.

Naredba №25/2005 (DV 64, 2005 and DV 80, 2005) Directive 25/2005 on the Requirements for Protection of Persons in Case of Chronic Exposure as a Result of Production, Trade and Use of Raw Materials, Products and Goods with Increased Content of Radionuclides (in Bulgarian). 